\section{Efficacy Of Several Salmonella Vaccination Programs Against Experimental Challenge With Salmonella Gallinarum In Commercial Brown Layer and Broiler Breeder Hens}

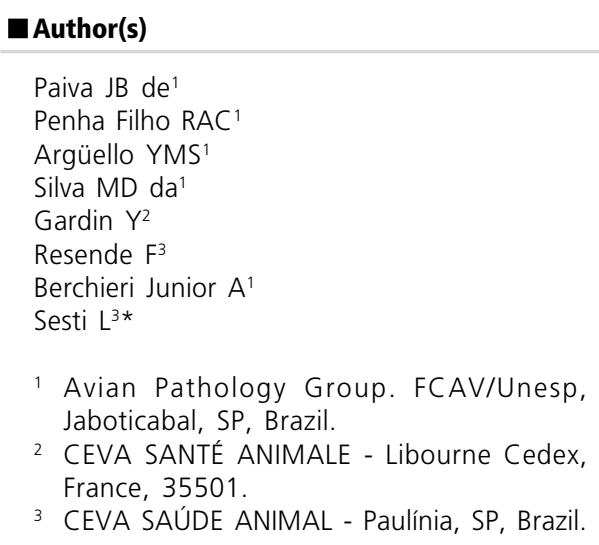

Mail Address
Luiz Sesti
Ceva Saúde Animal
Paulinia, SP, Brasil
Phone +55 1981360569
Fax +55 1938337722
E-mail: luiz.sesti@ceva.com

\section{Keywords}

Fowl Typhoid, killed Salmonella vaccines, live Salmonella vaccines, Salmonella Gallinarum, Salmonella Gallinarum challenge.

\section{ABSTRACT}

The protective effect of various Salmonella vaccines regimens against an experimental Salmonella Gallinarum challenge (SGNalr strain at 12 wk of age) was evaluated in two experiments. In Experiment 1 commercial brown layers were vaccinated according to one of the following programs: (i) two doses of a SE bacterin (Layermune SE; group 1); (ii) a first dose of a live SG9R vaccine (Cevac SG9R) followed by a SE bacterin (Layermune SE; group 2); (iii) one dose of each of two different multivalent inactivated vaccines containing SE cells (Corymune 4 \& Corymune 7; group 3) or (iv) not vaccinated (group 4). In Experiment 2, broiler breeders were given the same vaccination treatments except for the group vaccinated with the multivalent vaccines. Overall, in both experiments, all vaccination schemes were effective in reducing mortality after challenge with a SG field strain. Primary vaccination with an initial dose of a live SG9R vaccine followed some weeks later by a dose of an inactivated SE bacterin was the most effective $(p<0.05)$ vaccination program against mortality induced by field SG experimental challenge in both experiments.

In conclusion, Salmonella vaccination programs containing SE bacterins alone or in combination with a live SG9R vaccine are effective in preventing mortality induced by infection of field SG. Nevertheless, it is important to emphasize that any vaccination program against any Salmonella serotype will only be effective if it is part of a sound and comprehensive biosecurity program designed for Salmonella control in poultry farms.

\section{INTRODUCTION}

Salmonella enterica serovar Gallinarum (SG) is the etiologic agent of Fowl Typhoid, a severe systemic disease of chickens and other galliform birds (Shivaprasad, 2000). Salmonella Gallinarum is a non-motile hostspecific bacterium in domestic poultry. Infection in chickens occurs at all ages and is characterized by severe hepatomegaly and splenomegaly accompanied by liver with bronzing aspect, anemia, and septicemia (Shivaprasad, 2000). The disease is dose-dependent and differences in pathogenicity may be found depending upon the susceptibility of the infected genetic line of chickens (Oliveira et al., 2005).

S. Gallinarum is primarily associated with the mononuclear phagocyte system and resides prematurely within macrophages in the liver and spleen. SG can be found in the gastrointestinal tract early in the infection after oral contamination or at the final stage when the birds are dying (Barrow et al., 1994; Wigley et al., 2002). Regarding the epidemiology of fowl typhoid, the most important transmission route is horizontal, and very little information is available on direct evidences of transmission of the pathogen through the eggs to the progeny (Hall, 1949). S. 
Paiva JB de, Penha Filho RAC, Argüello YMS, Silva MD da, Gardin Y, Resende F, Berchieri Junior A, Sesti L

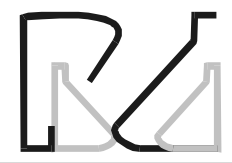

Gallinarum infection generally results either in mortality of susceptible birds or bacterial clearance in resistant birds within three to four weeks of the initial infection, although occasionally persistent infection may occur (Wigley et al., 2002; Wigley, 2004).

Mortality and morbidity rates due to Fowl Typhoid may reach up to $80 \%$. Fowl typhoid has been eradicated from Australia, North America, and most European countries, where rigorous biosecurity and specific control programs including vaccination and good management practices have been largely applied. However, it is still of considerable economic importance in many countries of Africa, Asia, and Central and South America (Pomeroy \& Nagajara, 1991; Lee et al., 2003). The most effective means of control is a combination of stringent biosecurity and management procedures and eradication (Calnek et al., 1997). Removal of birds that had died from disease from the environment, reduced the resultant mortality/morbidity and is regarded as a very useful measure for control of the Fowl Typhoid (Oliveira et al., 2005).

Vaccination to prevent or reduce Salmonella infection in poultry has been accepted worldwide. Presently in Brazil there are commercially available Salmonella Enteritidis (SE) bacterins and live attenuated Salmonella Gallinarum vaccines. Commercial layer and broiler industries in Brazil have gradually accepted routine vaccination as a preventive intervention method to reduce the Salmonella in industrial farms.

SE bacterins contain bacteria organisms that were inactivated and suspended in water-in-oil or aluminum hydroxide adjuvant. Bacterins stimulate high levels of circulating antibodies in commercial layers, which persist into the laying period (Timms et al., 1990; Barbour et al., 1993; Timms et al., 1994). Those SE bacterins provide cross-protection against $S$. Gallinarum and other serotypes. Some disadvantages of bacterins are the labor cost for administration and the post-vaccination stress due to tissue reaction at the site of injection, which is caused by the release of bacterial cell wall endotoxins subsequent to vaccine antigen metabolization in the birds (Nakamura et al., 1994).

For fowl typhoid prevention, inactivated Salmonella vaccines and live SG vaccine using the $9 R$ strain have been introduced (Lee et al., 2005). Killed vaccines can be efficacious in reducing Salmonella in poultry. They are safe because there is no reversion to virulence, no spreading in the environment and are considered good enough to protect chickens when applied in large-scale
Efficacy Of Several Salmonella Vaccination Programs Against Experimental Challenge With Salmonella Gallinarum In Commercial Brown Layer and Broiler Breeder Hens

poultry production (Barrow et al., 1991; De Buck et al., 2004). Nevertheless, live vaccines are considered to have advantages over killed vaccines as far as induced immunity is concerned (Van Immerseel et al., 2005). Live vaccines, by causing the expression of all appropriate antigens in vivo, induce better protection against Salmonella because they stimulate both cellmediated and humoral immunity and expression of all appropriate antigens in vivo, while inactivated ones mainly stimulate the production of antibodies only against the antigens present at the time of in vitro harvesting (Collins, 1974; Gast et al., 1993; Barrow \& Wallis, 2000). Killed vaccines may also be rapidly destroyed and eliminated from the host, and they are generally considered as unable to induce activation of cytotoxic T cells (Barrow \& Lovell, 1991; Nagajara \& Rajashekara, 1999). It is widely accepted that cellmediated immunity is more important than humoral responses in the protection against Salmonella, especially in infections caused by host-specific serotypes (Collins, 1974; Mastroeni et al., 1993; Van Immerseel et al., 2005; Barrow, 2007).

The strain $9 R$ of SG is routinely administered to chickens in countries with endemic fowl typhoid (Smith, 1956; Shivaprasad, 2000). The 9R strain developed in the 1950 s has a semi-rough lipopolysaccharide structure that reduces the virulence of that microorganism (Smith, 1956 a,b; Silva et al., 1981; Silva, 1984; Feberwee et al., 2001a,b). This vaccine may also provide some protection against Salmonella Enteritidis and Salmonella Typhimurium (Barrow et al., 1991; Audisio \& Terzolo, 2002; Tan et al., 2008ab). SG9R vaccine presented acceptable safety and efficacy in young layer hens even when administered at 4 weeks of age (Lee et al., 2005). In addition, no evidence of fecal shedding of the vaccine strain was found (Feberwee et al., 2000). However, there have been reports of SG9R vaccine strain fecal shedding for a maximum time of 24 hours after vaccination (Silva et al., 1981).

Live vaccine 9R strain induces cellular and humoral responses in chickens, and both immune responses reach their peaks at similar times. Bacterial clearance three weeks post-vaccination coincides with an increase in circulating anti-Salmonella antibodies, increased cytotoxic T cell proliferation directed to Salmonella cells, and increased expression of interferon gamma (Wigley et al., 2005). A slight increase in the expression of the pro-inflammatory cytokine interleukin-I $\beta$ was detected early in the infection (Wigley et al., 2005). 
Paiva JB de, Penha Filho RAC, Argüello YMS, Silva MD da, Gardin Y, Resende F, Berchieri Junior A, Sesti L

Some primary breeder and commercial layer producers administer the live SG or ST vaccine early in the pullets' life, followed by a SE bacterin at the end of rearing (Nassar et al., 1994; Schaller, 1996; Cookson \& Maiers, 2004). The combined use of live and killed vaccines had not been studied at that time, but a broader range of protection against other serotypes with this live/killed vaccine approach would certainly be expected.

This study assessed the efficacy of commercial killed $S E$ vaccines alone or in combination with a commercial live SG9R vaccine in controlling an experimental SG challenge.

\section{MATERIAL AND METHODS}

\section{Birds}

Female birds from a commercial strain of brown table-egg layers (Dekalb white; Granja Planalto, Uberlândia, MG, Brazil) were used in the Experiment 1. Brown layers are highly susceptible to Salmonella Gallinarum infections (Berchieri Jr. et al., 2000; Freitas, et al., 2007). In Experiment 2, female birds from a commercial strain of broiler breeders (Cobb 500; CobbVantress Brasil, Guapiaçú-SP-Brazil) were used. They were obtained at one day of age and were reared and fed according to the recommendations of the production manuals of each strain.

At arrival, all birds were inspected according to Zancan et al. (2000) to confirm if they were free from Salmonella sp infection and antibodies against SE.

All birds were housed in the same house in separate sets of five cages containing 6 birds each (Experiment 1) or sets of four cages containing 5 birds each (Experiment 2). Experiment 2 was carried out first, and there was a downtime period of few weeks for cleaning and disinfection before Experiment 1 started.

\section{Vaccines}

The vaccines used were commercial vaccines produced by CEVA-Phylaxia (Cevac Corymune 4K \& 7K; Budapest, Hungary), CEVA Biomune (Layermune SE; Lenexa, USA), and CEVA Campinas (Cevac SG9R; Campinas, Brazil).

Cevac Corymune $4 \mathrm{~K}$ contains an inactivated combination of Avibacterium paragallinarum serotypes A, B and C, and Salmonella Enteritidis strain, homogenized with aluminum hydroxide adjuvant and thiomersal as a preservative. Cevac Corymune 7K contains an inactivated combination of Avibacterium paragallinarum serotypes A, B and C, Salmonella
Efficacy Of Several Salmonella Vaccination Programs Against Experimental Challenge With Salmonella Gallinarum In Commercial Brown Layer and Broiler Breeder Hens

Enteritidis strain, La Sota strain of Newcastle Disease virus, Massachussetts strain of the Infectious Bronchitis virus, and B8/78 strain of the EDS virus, homogenized with oil adjuvant and thiomersal as a preservative. Layermune SE is an inactivated bacterial vaccine (bacterin) that contains multiple selected strains of Salmonella Enteritidis (SE) in oil adjuvant. Cevac SG9R contains live Salmonella Gallinarum strain (strain 9R; at least $10^{7} \mathrm{CFU}$ per dose) naturally attenuated and non-pathogenic for chicken, in freeze-dried form.

At 5 and 9 weeks of age, birds in each group were either vaccinated intramuscularly in the breast muscle (Cevac Corymune 4K \& 7K and Layermune SE) or subcutaneously in the dorsal lower part of the neck (Cevac SG9R) as recommended by the manufacturers.

\section{Challenge}

A virulent Salmonella Gallinarum 9S strain, isolated from diseased chickens was used. A spontaneous mutant isolate resistant to nalidixic acid (SGNalr) was used to allow recovery.

The inocula consisted of overnight cultures in LB broth (DIFCO-244620) prepared in shaking incubator (100rev/min) at $37^{\circ} \mathrm{C}$ for $24 \mathrm{~h}$. These cultures contained approximately $8 \times 10^{8}$ colony forming units $(\mathrm{CFU}) / \mathrm{mL}$.

At 12 weeks of age all chickens were orally inoculated directly into the crop with $2 \mathrm{~mL}$ of a broth culture of the bacterial strain.

\section{Experimental design}

\begin{tabular}{|c|c|c|c|}
\hline \multirow{2}{*}{$\begin{array}{l}\text { Group } \\
\text { (\# of birds) }\end{array}$} & \multicolumn{2}{|c|}{ Vaccination program } & \multirow{2}{*}{$\begin{array}{c}\text { SG Challenge } \\
\text { at } 12 \mathrm{wk} \text { of age } \\
(2 \mathrm{~mL} \text { containing } \\
\left.\sim 8 \times 10^{8} \text { CFU per } \mathrm{mL}\right)\end{array}$} \\
\hline & $\begin{array}{l}\text { 1st dose } \\
\text { (5 wk) }\end{array}$ & $\begin{array}{c}\text { 2nd dose } \\
\text { (9 wk) }\end{array}$ & \\
\hline $1(30)$ & Layermune SE & Layermune SE & SGNalr \\
\hline $2(30)$ & Cevac SG9R & Layermune SE & SGNalr \\
\hline $3(30)$ & Corymune $4 \mathrm{~K}$ & Corymune 7K & SGNalr \\
\hline $4(30)$ & Not vaccinated & Not vaccinated & SGNalr \\
\hline
\end{tabular}

\begin{tabular}{|c|c|c|c|}
\hline \multirow{2}{*}{$\begin{array}{l}\text { Group } \\
\text { (\# of birds) }\end{array}$} & \multicolumn{2}{|c|}{ Vaccination program } & \multirow{2}{*}{$\begin{array}{l}\text { SG Challenge } \\
\text { at } 12 \text { wk of age } \\
(2 \mathrm{~mL} \text { containing } \\
\left.\sim 8 \times 10^{8} \text { CFU per } \mathrm{mL}\right)\end{array}$} \\
\hline & $\begin{array}{l}\text { 1st dose } \\
\text { (5 wk) }\end{array}$ & $\begin{array}{c}\text { 2nd dose } \\
\text { (9 wk) }\end{array}$ & \\
\hline $1(20)$ & Layermune SE & Layermune SE & SGNalr \\
\hline $2(20)$ & Cevac SG9R & Layermune SE & SGNalr \\
\hline $3(20)$ & Not vaccinated & Not vaccinated & SGNalr \\
\hline
\end{tabular}

For the two experiments, mortality was recorded 
Paiva JB de, Penha Filho RAC, Argüello YMS, Silva MD da, Gardin $Y$, Resende F, Berchieri Junior A, Sesti L

over a period of 28 days post-infection. Mortality rates were analyzed using the Chi-Square test $(p<0.05)$.

\section{RESULTS}

All birds in both experiments were completely negative for Salmonella spp at arrival.

Experiment 1. Cumulative mortality data in commercial brown layer hens are shown in Table 1 and Figure 1. A considerable reduction in mortality was observed in the groups of birds vaccinated with SE inactivated vaccines (Groups 1 and $3 ; p<0.05$ ). No mortality occurred in brown layer hens vaccinated with a live SG9R vaccine (Cevac SG9R) plus an inactivated bacterin (Layermune SE).

Experiment 2. Cumulative mortality data in broiler breeder hens are shown in Table 2 and Figure 2. Both vaccination schemes reduced mortality during the fourweek period after challenge. However, protection was significant (lower mortality; $p<0.05$ ) only in birds vaccinated initially with the live SG9R vaccine (Cevac SG9R) followed by a dose of the inactivated SE vaccine (Layermune SE).

\section{DISCUSSION}

The primary source of $S$. Gallinarum infection in poultry flocks is other infected poultry and vertical transmission; thus, introduction of these organisms in poultry flocks can be reasonably well controlled by
Efficacy Of Several Salmonella Vaccination Programs Against Experimental Challenge With Salmonella Gallinarum In Commercial Brown Layer and Broiler Breeder Hens

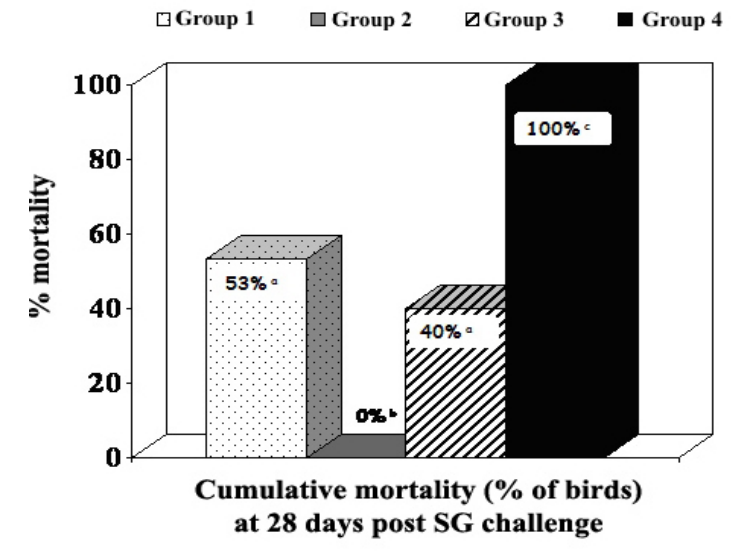

Figure 1 - Cumulative \% mortality of commercial brown layer hens four weeks post-challenge with Salmonella Gallinarum (bars with \% followed by different superscript letters are statistically different $[p<0.05])$.

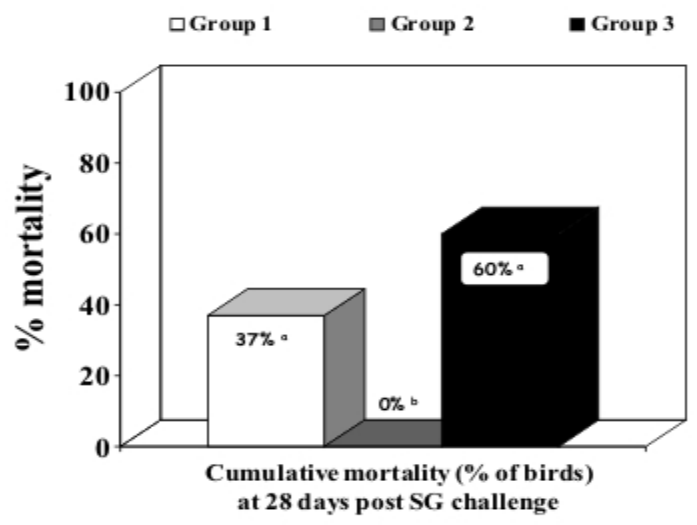

Figure 2- Cumulative \% mortality of broiler breeder hens four weeks post-challenge with Salmonella Gallinarum (bars with \% followed by different superscript letters are statistically different $[p<0.05])$.

Table 1 - Cumulative mortality of commercial brown layers hens vaccinated at 5 and 9 weeks old and challenged at 12 weeks old with Salmonella Gallinarum (total mortality figures [\# of dead birds / total] followed by different superscript letters are statistically different $[2 ; p<0.05])$.

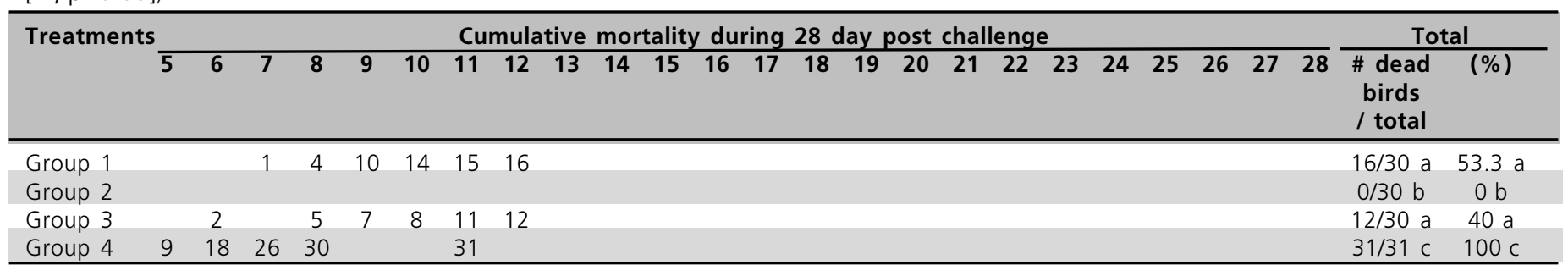

Table 2 - Cumulative mortality of broiler breeder hens vaccinated at 5 and 9 weeks old and challenged at 12 weeks old with Salmonella Gallinarum (total mortality figures [\# of dead birds / total] followed by different superscript letters are statistically different [ $2 ; \mathrm{p}<0.05$ ]).

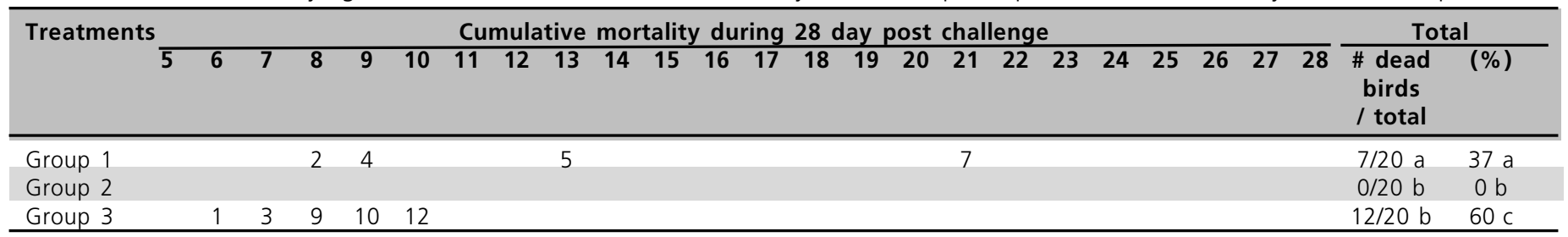


Paiva JB de, Penha Filho RAC, Argüello YMS, Silva MD da, Gardin Y, Resende F, Berchieri Junior A, Sesti L

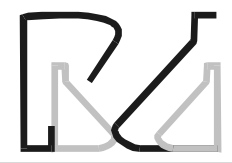

standard biosecurity measures to minimize the risk of contact with infected flocks or people, equipment, and other fomites that may have originated from an infected site (Shivaprasad, 2003). However, in high field infection pressure farms, particularly multiage ones, vaccination presents an additional and effective control tool (Barrow, 2007).

Killed vaccines have been used to control Salmonella infections in poultry with variable success. Killed vaccines protect chickens against massive Salmonella challenge (particularly the non-typhoid serotypes) at any age (Timms et al., 1994). Nonetheless, they may reduce but not totally eliminate the microorganism from internal organs (Gast et al., 1993), perhaps because humoral immunity alone is unlikely to fully protect against SE, as complete protection against Salmonella requires the induction of both humoral and cellular immunity (Miyamoto et al., 1999). Notwithstanding, the recent development of novel adjuvant technology is very promising for the development of totally safe, inactivated Salmonella vaccines capable of inducing potent immune stimulation targeting different weapons of the chickens' immune system (Barrow, 2007).

It has been proposed that cell-mediated immunity is more important than humoral immunity for tissue clearance of Salmonella, whereas humoral responses seem to be the key in reducing intestinal colonization (Hassan \& Curtiss 1994; Barrow \& Wallis, 2000; Babu et al., 2004 ). An ideal vaccine should promote protection of birds against mucosal and systemic infection by effectively stimulating both immune responses (Van Immerseel et al., 2005). Although some authors (Barrow \& Wallis, 2000; Meyer et al., 1992, Zhang-Barber, 1999) demonstrated that killed Salmonella vaccines induce only partial immune response, in the present work this response was good enough to significantly prevent mortality in the groups of birds challenged with a virulent SGNalr strain $(p<$ 0.05 ). These findings are very interesting since the same vaccines were also assessed against a SE challenge and demonstrated significant efficacy (Penha Filho et al., unpublished data). Salmonella Gallinarum and Salmonella Enteritidis belong to the same serogroup (D1) and share the same "O' somatic antigenic formula (1,9,12; Ewing, 1986) which explains the cross protection provided by the SE bacterin against SG (Kingley \& Baumler, 2000). It has been demonstrated that Salmonella vaccines can elicit crossimmunity against members of the same serogroup. The ability of a SE bacterin to cross protect against other
Efficacy Of Several Salmonella Vaccination Programs Against Experimental Challenge With Salmonella Gallinarum In Commercial Brown Layer and Broiler Breeder Hens

Salmonella has been demonstrated by field use in Latin America (Norton \& Lozano, 1997). In an endemically SG-contaminated layer farm, cumulative mortality by Fowl Typhoid during an $11 \mathrm{wk}$ period was significantly lower in a house where birds were vaccinated with a SE bacterin (1.8\% mortality) as compared to the average mortality in non-vaccinated houses $(8.1 \%$ mortality; Norton and Lozano, 1997).

According to Liu et al. (2001), inactivated vaccines can decrease SE fecal excretion and that effect may depend on their composition. A study conducted by Barbour et al. (1993) comparing six inactivated SE vaccines showed variable reduction in SE fecal excretion. The same was observed by Freitas et al. (2008) comparing three commercial SE bacterins. These authors suggested that several factors could be responsible for this effect, such as adjuvant type and composition, Salmonella Enteritidis strain, inactivation method, etc. These factors could explain the different protection results observed in birds vaccinated with Layermune SE or Corymune bacterins in Experiment 1, although in the present study a SG and not a SE challenge was used. There is very scarce information on the effectiveness of Salmonella Gallinarum inactivated bacterins. In the recent article of Haider et al. (2007), it was demonstrated that a SG bacterin made from field isolates was able to induce significant seroconversion, although no information was provided in regard to protection against an experimental challenge.

In the present experiments, the best protection was observed in groups of birds vaccinated with the live $S G 9 R$ vaccine. Vaccination against host-specific Salmonella serotypes that cause severe systemic disease induces strong serotype-specific protective immunity (Smith, 1956; Barrow \& Wallis, 2000).

A number of studies (Smith, 1956; Harbourne, 1957; Gordon \& Luke, 1959; Gordon et al., 1959; Lee et al., 2005) have shown that the SG9R vaccine strain as an effective means for fowl typhoid prevention. Mortality in highly susceptible chicks exposed to virulent strains of S. Gallinarum was limited by SG9R vaccine (Silva et al., 1981). Lee et al. (2005) showed that a 9R vaccine provided excellent protection and is safe for vaccination of 4 week-old chickens. Indeed, in the present studies, birds that received the SG9R strain by subcutaneous route showed no evidence of disease, while SGNalr challenge strain was highly virulent to both genetic lines of birds assessed.

In this study we did not find any differences in the protection induced by the SG9R vaccine among the 
Paiva JB de, Penha Filho RAC, Argüello YMS, Silva MD da, Gardin Y, Resende F, Berchieri Junior A, Sesti L

genetic lines used in both experiments. However, the vaccination program with two doses of an inactivated SE bacterin (Layermune SE + Layermune SE) apparently had lower effectiveness, which may indicate lower susceptibility to fowl typhoid by meat-type chickens. Regardless possible differences in susceptibility to a SG challenge and despite of the genetic evolution of commercial bird lines throughout the past decades, the present situation is similar to that previously described by Gordon et al. (1959). Notwithstanding Bumstead et al. (1993) state that the modern genetic lines of commercial birds exhibit different patterns of immunity to Salmonella.

There is quite little scientific information available in literature on the control of Fowl Typhoid through vaccination programs adopting live and inactivated Salmonella vaccines. However, several published experiments indicate that such combination programs using live (including the SG9R strain) plus inactivated Salmonella vaccines can be very effective against SE infections in layer hens (Nassar et al., 1994; Schaller, 1996; Cookson \& Maiers, 2004). It is not possible to directly compare our study with the previously mentioned SE experiments as the vaccination schemes and vaccines used are quite different. However, it stands very clear that the combination of an initial live Salmonella vaccine followed some weeks later by an inactivated product may be a very useful and effective program in preventing fowl typhoid.

In conclusion, vaccination programs containing SE bacterins alone or in combination with a live SG9R vaccine induced variable protection against mortality caused by infection of field SG, depending on the specific vaccination program used. Bacterins only, although having significantly decreased mortality in challenged brown layers, did not have a significant effect on broiler breeder hens. The combination of an initial dose of a live SG9R vaccine followed some weeks later by a dose of an inactivated SE bacterin was the most effective vaccination program.

Nevertheless, it is crucial to emphasize that any vaccination program against any Salmonella serotype will only be effective if it is part of a sound and comprehensive biosecurity program designed for Salmonella control.

\section{REFERENCES}

Audisio MC, Terzolo HR. Virulence Analysis of a Salmonella gallinarum strain by oral inoculation of 20-day-old chickens. Avian Diseases 2002; 46:186-191.
Efficacy Of Several Salmonella Vaccination Programs Against Experimental Challenge With Salmonella Gallinarum In Commercial Brown Layer and Broiler Breeder Hens

Babu U, Dalloul RA, Okamura M, Lillehoj HS, Xie H, Raybourne RB, Gaines D, Heckert RA. "Salmonella enteritidis Clearance and Immune Response in Chickens Following Salmonella Vaccination and Challenge." Veterinary Immunology and Immunopathology 2004; 101(3-4):251-7

Barbour EK, Wayne WM, Nabbut NH, Poss PE, Brinton MK. Evaluation of bacterins containing three predominant phage types of Salmonella enteritidis for prevention of infection in egg laying chickens. American Journal of Veterinary Research 1993; 54:13061309

Barrow PA. Salmonella infection: immune and non-immune protection with vaccines. Avian Pathology 2007; 36(1):1-13.

Barrow PA, Lovell MA, Berchieri Jr A. The use of two live attenuated vaccines to immunize egg-laying hens against Salmonella enteritidis phage type 4. Avian Pathology 1991; 20: 681-692.

Barrow PA, Lovell MA. Experimental infection of egg-laying hens with Salmonella enteritidis phage type 4. Avian Pathology 1991; 20:335-348

Barrow PA, Wallis TS. Vaccination against Salmonella infections in food animals: rationale theoretical basis and practical applications In: Wray C, Wray A, editors. Salmonella in domestic animals. New York: CABI Publishing; 2000. p.323-339

Berchieri Jr A, Oliveira GH, Pinheiro LAP, Barrow PA. Experimental Salmonella Gallinarum infection in light laying hens lines. Brazilian Journal of Microbiology 2000; 31:50-52.

Bumstead N, Barrow P. Resistance to Salmonella gallinarum S. pullorum and S. enteritidis in inbred lines of chickens. Avian Diseases 1993; 37:189-193.

Calnek BW, Barnes HJ, Beard CW, MsDougald LR, Saif YM. Pullorum diseases and fowl typhoid. In: Shivaprassad HN, editor. Disease of poultry. 10th ed. Ames: lowa State University Press; 1998. p. 220228

Collins FM. Vaccines and cell-mediated immunity. Bacteriology Review 1974; 38(4):371-402.

Cookson KC, Maiers JD. SE protection of commercial layers vaccinated with attenuated live $S$ typhimurium boosted with killed SE bacterin then challenged during molt" a portion of a presentation. USAHA 108'h Annual Meeting Greenville; 2004 oct 21-24; Guenville, NC.

De Buck J, Van Imerseel F, Haeseberouck F, Ducatelle R. Effect of type fimbriae of Salmonella enterica serotype Enteritidis on bacteraemia and reproductive tract infection in laying hens. Avian Pathology 2004; 33:314-320.

Ewing WH. Edwards and Ewing's identification enterobacteriaceae. 4th ed. New York: Elsevier; 1986.

Feberwee A, Hartman EG, De Wit JJ, De Vries TS. The spread of Salmonella gallinarum $9 R$ vaccine strain under field conditions. Avian Diseases 2001a; 45:1024-1029. 
Paiva JB de, Penha Filho RAC, Argüello YMS, Silva MD da, Gardin Y, Resende F, Berchieri Junior A, Sesti L

Feberwee A, de Vries TS, Hartman EG, de Wit JJ, Elbers AR, de Jong WA. Vaccination Against Salmonella enteritidis in Dutch Commercial Layer Flocks with a Vaccine Based on a Live Salmonella gallinarum 9R Strain: Evaluation of Efficacy Safety and Performance of Serologic Salmonella Tests". Avian Diseases 2001b; 45:83-91.

Freitas OC, Arroyave W, Alessi AC, Fagliari J J, Berchieri Jr A. Infection of commercial laying hens with Salmonella Gallinarum: Clinical anatomopathological and haematological studies. Brazilian Journal of Poultry Science 2007; 9:133-141.

Freitas OC, Mesquita AL, Paiva JB, Zotesso F, Berchieri Jr A. Control of Salmonella enterica serovar Enteritidis in laying hens by inactivated Salmonella Enteritidis vaccine. Brazilian Journal of Microbiology 2008; 39:390-396.

Gast RK, Stone HD, Holt PS. Evaluation of the efficacy of oil-emulsion bacterins for reducing fecal shedding of Salmonella Enteritidis by laying hens. Avian Disease 1993; 37:1085-91.

Gordon RF, Garside JS, Tucker JF. The use of living attenuated vaccines in the control of fowl typhoid. Veterinary Record 1959; 71:300-305.

Gordon WAM, Luke D. A note on the use of the 9R fowl typhoid vaccine in poultry breeding flocks. Veterinary Record 1959; 71:926927.

Haider MG, Rahman MM, Hossain MM, Rashid M, Sufian MA, Islam MM, Haque AFM. Production of formalin killed fowl typhoid vaccine using local isolates of Salmonella Gallinarum in bangladesh Bangladesh. Journal of Veterinary Medicine 2007; 5(1-2):33-38.

Hall WJ, Legenhausen DH, MacDonald AD. Studies on fowl typhoid 1 Nature and dissemination. Poultry Science 1949; 28:344-362.

Harbourne JF. The control of fowl typhoid in the field by the use of live vaccines. Veterinary Record 1957; 69:1102-1107.

Hassan JO, Curtiss R. Development and evaluation of an experimental vaccination program using a live avirulent Salmonella Typhimurium strain to protect immunized chickens against challenge with homologous and heterologous Salmonella serotypes. Infection and Immunity 1994; 62:5519-5527.

Kingsley RA, Baumler AJ. Salmonella interactions with professional phagocytes. In: Oelschlaeger TA, Hacker J. Bacterial invasion into eukaryotic cells. New York: Kluwer Academic/Plenum; 2000. p 321342.

Lee YJ, Kim KS, Kwon YK, Tak RB. Biochemical characteristics and antimicrobial susceptibility of Salmonella Gallinarum isolated in Korea. Journal of Veterinary Science 2003; 4:161-166.

Lee YJ, Mo IP, Kang MS. Sefety and efficacy of Salmonella gallinarum $9 R$ vaccine in young laying chickens. Avian Pathology 2005; 34(4):362-366.

Liu W, Yang Y, Chung N, Kwang J. Induction of humoral immune responses and protective immunity in chickens against Salmonella Enteritidis after a single dose of killed bacterium-loaded microspheres. Avian Diseases 2001; 45:797-806.
Efficacy Of Several Salmonella Vaccination Programs Against Experimental Challenge With Salmonella Gallinarum In Commercial Brown Layer and Broiler Breeder Hens

Mastroeni P, Villarreal-Ramos B, Hormaeche CE. Adoptive transfer of immunity to oral challenge with virulent Salmonellae in innately susceptible BALB/c mice requires both immune serum and $T$ cells. Infection and Immunity 1993; 61:3981-3984.

Meyer H, Barrow PA, Pardon P. Salmonella immunization in animals. Proceedings of the International Symposium on Salmonella and Salmonellosis; 1992 sept 15-17. Ploufragan, FRA. p.345-374.

Miyamoto T, Kitaoka GS, Withanage T, Fukata K, Sasai E. Evaluation of the efficacy of Salmonella enteritidis oil-emulsion bacterin in an intravaginal challenge model in hens. Avian Diseases 1999; 43:497505.

Nakamura M, Nagamine N, Takahashi T, Suzuki S, Sato S. Evaluation of the efficacy of a bacterin against Salmonella enteritidis infection and the effect of stress after vaccination. Avian Diseases 1994; 38:717-724.

Nagaraja KV, Rajashekara G. Vaccination against Salmonella enterica serovar Enteritidis infection: dilemma and realities In: Saeed AM, editors. Salmonella enterica serovar Enteritidis in humans and animals. Ames: lowa State University Press; 1999. p.397-404.

Nassar TJ, al-Nakhli HM, al-Ogaily ZH. Use of Live and Inactivated Salmonella enteritidis phage type 4 vaccines to immunise laying hens against experimental infection. Reviews in Science and Technology Office International de Epizootiologie 1994; 13:85567.

Norton ECG, Lozano F. Evaluación económica del uso de una bacterina contra Salmonella Enteritidis en ponedoras comerciales. Anais do 15th Congresso Latino Americano de Avicultura; 1997; Cancún, MEX. p.252-254.

Oliveira GH, Fernandes AC, Berchieri Jr A. Experimental infection of laying hen with Salmonella Gallinarum. Brazilian Journal of Microbiology 2005; 36:51-56.

Pomeroy BS, Nagaraja KV. Fowl typhoid In: Calnek BW, Barnes HJ, Beard CW, Reid WM, Yoder HW, editors. Poultry disease. Ames: lowa State University Press; 1991. p 87-98.

Schaller G. Decision criteria for vaccination against Salmonella in poultry. Acta Veterinaria Scandinavia 1994; 90 (suppl):69-71.

Shivaprasad HL. Fowl typhoid and pullorum disease. Review in Scientific Technologies (OIE) 2000; 19(2):405-424.

Shivaprasad HL. Pulllorum disease and fowl typhoid In: Saif YM, Barnes HJ, Fadly AM, Glisson JR, McDougald LR, Swayne DE, editors. Diseases of poultry. Ames: lowa State Press; 2003. p.568-582.

Silva EN, Snoeyenbos GH, Weinack OM and Smyser CF. Studies on the use of 9R strain of Salmonella gallinarum as a vaccine in chickens. Avian Diseases 1981; 25:38-52.

Silva EN. The Salmonella gallinarum problem in Central and South America. Proceedings of the International Symposium on Salmonella; 1984; New Orleans. p.150-156.

Smith HW. The use of live vaccines in experimental Salmonella 
Paiva JB de, Penha Filho RAC, Argüello YMS, Silva MD da, Gardin Y, Resende F, Berchieri Junior A, Sesti L
Efficacy Of Several Salmonella Vaccination Programs Against Experimental Challenge With Salmonella Gallinarum In Commercial Brown Layer and Broiler Breeder Hens

gallinarum infections in chickens with observations on their interference effect. Journal of Hygiene 1956a; 54: 419-432.

Smith HW. The immunity to Salmonella Gallinarum infection in chickens produced by live cultures of members of the Salmonella genus. The Journal of Hygiene 1956b; 54:433-439.

Tan TZ, Nay B, Bricker JM, Hughes H, Sterner F, Hein R. An attenuated Salmonella gallinarum live vaccine induces long term protection against Salmonella enteritidis challenge in chickens [cited 2000 dec 30]. Available from: http://wwwsafe-poultrycom/ publicationsasp.

Tan TZ, Nay B, Bricker JM, Witvliet M, Hughes H, Sterner F, Hein R. Safety Studies and risk analysis of an attenuated Salmonella gallinarum live vaccine for layer chickens [cited 2000 dec 30]. Available from: http://wwwsafe-poultrycom/publicationsasp.

Timms LM, Marshall RN, Breslin MF. Laboratory assessment of protection given by an experimental Salmonella enteritidis PT4 inactivated adjuvant vaccine. Veterinary Record 1990; 127:611614.

Timms LM, Marshall RN, Breslin MF. Laboratory and field-trial assessment of protection given by Salmonella enteritidis PT4 inactivated adjuvant vaccine British. Veterinary Journal 1994; 150 : 93-102.

Van Immersel F, Methner U, Rvchlik I, Velge P, Martin G, Foster N, Ducatelle $R$, Barrow PA. Vaccination and early protection agains nos-host-specific Salmonella serotypes in poultry: exploitation of innate and microbial activity. Epidemiology and Infection 2005; 33:959-978.

Wigley P, Hulme SD, Bumstead N, Barrow PA. In vivo and in vitro studies of genetic resistance to systemic salmonellosis in the chicken encoded by SALI locus. Microbes and Infection 2002; 4(11):11111120.

Wigley P. Genetic resistance to Salmonella infection in domestic animals. Research in Veterinary Science 2004; 76:165-169.

Wigley P, Hulme S, Powers C, Beal R, Smith A, Barrow P. Oral infection with the Salmonella enterica serovar Gallinarum $9 R$ attenuated live vaccine as a model to characterise immunity to fowl typhoid in the chicken. BMC Veterinary Research 2005; 1:1-6.

Zancan FB, Berchieri Jr A, Fernandes SA, Gama NMSQ. Salmonella spp investigation in transport box of day old birds. Brazilian Journal of Microbiology 2000; 31:230-232.

Zhang-Barber L, Turner AK, Barrow PA. Vaccination for control of Salmonella in poultry. Vaccine 1999; 17:2538-2545. 